\title{
Knowledge and Practice of Injection Safety in Routine Immunization among Health Care Workers in Primary Health Care Centres in South West Nigeria
}

\author{
Uwaibi NE ${ }^{1}$ Omozuwa $\mathrm{ES}^{2}$ and Omuemu $\mathrm{VO}^{3}$ \\ Research scholar ${ }^{1-2}$ and professor ${ }^{3}$ \\ ${ }^{* 1}$ Community Medicine Department, Edo University Iyamho km 7 Auchi-Abuja road Edo state, Nigeria \\ ${ }^{2}$ Department of Obstetrics and Gynaecology, Edo University Iyamho, km7 Auchi-Abuja Express Road, \\ Auchi, Edo state \\ ${ }^{3}$ Community Health Department, University of Benin Teaching Hospital, Benin City Edo State, Nigeria
}

\begin{abstract}
Background and objective of the study: The recent increase of immunization services, including the elimination and control campaigns, offered an opportunity for improvement and made it imperative that injections are safe for people the objective of the study was to assess the knowledge and practice of injection safety among healthcare providers in primary health care centres

Materials and Methods: A descriptive cross sectional study was utilised. A semi structured interviewer administered questionnaire with open and closed ended questions was used to collect information on knowledge and practice of injection safety among health workers. The questionnaire was adapted and modified from the WHO revised tool for injection safety among 270 primary health care workers.
\end{abstract}

Results: The mean age of the respondents was $=41.4 \pm 8.7$ years. The Majority had good knowledge of injection safety but 162 (60.0\%) had fair practice.

Conclusion: The Majority had good knowledge of injection safety but the practice was fair.

Keywords: Knowledge, Practice, Injection Safety, Routine Immunization, Healthcare Workers.

\section{INTRODUCTION}

The increase of immunization services, including the elimination and control campaigns, has offered an opportunity for improvement and made it imperative that injections are safe for people. In the developing world, routine immunization of children under one year accounts for over one billion injections while routine immunizations for measles control/elimination activities and disease-outbreak control operations delivered more than 200 million injections in 1999 [1].

The WHO and UNICEF has implemented a strategy to ensure that special attention is paid to the safe administration of vaccines, both in routine immunization services and during mass campaign.37Injection safety is a key element of patient and healthcare worker safety [2]. It is supported by infection prevention and control policies and procedures such as hand hygiene, good housekeeping and waste management. It is also a critical item of the continuous quality improvement (CQI) programme, managed by the healthcare team in the primary health facilities [2].

Injection safety practices involve ensuring safe injection practices are carried out at every routine immunization session by using the "nine rights," of appropriate injection safety. The "nine rights" of injection safety ensures that the right patient is given the right drug, in the right dosage and right formulation using the right injection equipment, at the right time and right route, with right storage and the right method of disposal [3-5]. Any breech of this, makes the injection unsafe and hazardous to the child and health care provider ${ }^{[6]}$ Unsafe injection practices are associated with risks to healthcare workers especially doctors, nurses, laboratory scientist, laundry worker and it is implicated in the transmission of infections such as Hepatitis B and C and Human Immunodeficiency Virus (HIV) [2]. 
According to World Health Organization (WHO), 90-95\% of injections administered in developing countries are for therapeutic purposes but only 5 to $10 \%$ are given for immunization. ${ }^{[7]}$ Routine immunization programmes account for approximately 750 million injections use yearly, and these injections are believed to be essential and safer than many non-immunization injections in most countrie ${ }^{s[8]} \mathrm{RI}$ injections are only safe when the correct vaccine is properly administered with sterile equipment that is disposed of safely after use. Globally unsafe infection practices cause about 5\% of HIV, 40\% of Hepatitis C and 32\% of Hepatitis B virus infections.About $30 \%$ to $50 \%$ of injection practices in developing countries are unsafe. ${ }^{[9,10]}$ This could lead to abscesses and life threatening infectious diseases. The burden of unsafe injection practices in RI is borne by the injection providers (health care workers), the patients, and the community. Injection providers are exposed to hazards of needle stick injuries from inadequate supply of appropriate sharp containers, unsafe practices such as recapping of needles, manipulating used sharps (bending, breaking, or cutting hypodermic needles), and carelessly passing sharps from one health care worker to another. Patients are exposed to the hazards of unsafe injection practices from sharps carelessly left in unexpected places like linen, when aseptic technique is not observed by healthcare workers and administration of drug at incorrect anatomical sites ${ }^{[10]}$ The community is also at risk of problems due to unsafe injections by, unsafe waste disposal practices such as improperly placed disposal sites, improper disposal methods like the use of shallow pits, and open dumping in unsecured pits. Unsafe injections also has socioeconomic and psychological consequences on the individual and the health system of a country. ${ }^{[10]}$ It is imperative that great care be given to providing these immunizations with only sterile injection equipment, otherwise children may be subjected to infections such as Hepatitis and HIV [9].

Health workers are important agents in the implementation of immunization programs, therefore poor knowledge of injection safety in RI could affect their practice and lead to reduce potency of the vaccines and increase adverse effects following immunization (AEFI) ${ }^{[11]}$ This study will help to find out health care workers knowledge and practices of safe injection use in RI. Observed gaps will help to formulate and develop training manual guidelines and modalities for HCW and PHCs. objectives of the study was to assess the knowledge and practice of injection safety in routine immunization among primary healthcare workers in primary health care centres

\section{MATERIAL AND METHODS}

The study was a descriptive cross-sectional study design, with a mixed method of data collection approach (incorporating quantitative and qualitative methods) conducted among health care workers involved in immunization services at the primary health care centres across the three Local Government areas in Benin City, Edo State. The study population consisted of all the health workers involved in immunization at the entire primary health facilities (nurses, CHO, CHEWs and JCHEWs) were interviewed. The minimum sample size required for this study was determined using the formula for studying single proportion [12], was 162 however data was collected from 270 health care workers. Ethical clearance to conduct this research was sought and obtained from the University of Benin Teaching Hospital Ethics and Research Committee and Permission was sought from the Permanent Secretary, Edo State Hospital Management Board and Chairpersons of the Local Government Areas while individual informed consent was sought from the respondents with full assurance of confidentiality. Only respondents who gave consent where used for the study

- The PHC workers were interviewed using the health worker questionnaire. A semi structured interviewer administered questionnaire with open and closed ended questions was used to collect information on knowledge and practice of injection safety from the primary health care workers. The questionnaire was adapted and modified from the WHO revised tool for injection safety (WHO/EHT/08.08) [13]. Repeated visit were made to the PHC centre until all the workers were interviewed

Ten questions were used to assess knowledge of health workers on injection safety. Each correct response was given a score of 1 while an incorrect response a score of 0 , with a maximum score of 20 . The total score of each health worker's response was converted to percentages and categorised as knowledge score of less than 50\% poor knowledge, 50 to $74.9 \%$ as fair knowledge while a score of $75 \%$ and above was adjudged good knowledge.

Twelve questions on practice of injection safety were also scored for correctness using the WHO revised tool for injection safety as standard.103 A positive response was given a score of 1 while a negative response a score of 0 with a maximum score of 24 . The total score of each health worker was converted to percentage and classified as: poor practice less than 50\% and good practice from $50 \%$ and above. The chi squared test and fishers exact test were carried out where applicable and the level of significance was set at a $\mathrm{p}$ value less than 0.05

\section{RESULTS}

A total of 270 primary health care workers were interviewed and their socio demographic characteristics are as shown in (table 1). One hundred and fifteen (42.6\%) of the healthcare workers were aged 40 - 49 years, $84(31.1 \%)$ were aged 30 - 39 years while 48 
$(17.8 \%)$ were aged $50-59$ years, with a Mean age $=41.4 \pm 8.7$ years; with $180(66.7 \%)$ of the respondents females while 90 $(33.3 \%)$ were males.

Sixty three (23.3\%) were JCHEWs, $62(23.0 \%)$ were public health nurses while 50 (18.5\%) were SCHEWs. Fifty three (19.6\%) were heads of their units while $217(80.4 \%)$ were healthcare providers.

One hundred and three (38.1\%) had worked for 4 years or less, $66(24.4 \%)$ had 5 - 9 years' experience while $54(20.0 \%)$ had $10-$ 14 years' experience with a Mean work experience $=8.2 \pm 6.5$ years

Table 1: Socio-demographic characteristics of the Healthcare workers

\begin{tabular}{|c|c|c|}
\hline Variable & Frequency $(n=270)$ & Percent \\
\hline \multicolumn{3}{|l|}{ Age (years) } \\
\hline $22-29$ & 23 & 8.5 \\
\hline $30-39$ & 84 & 31.1 \\
\hline $40-49$ & 115 & 42.6 \\
\hline $50-59$ & 48 & 17.8 \\
\hline \multicolumn{3}{|l|}{ Sex } \\
\hline Male & 90 & 33.3 \\
\hline Female & 180 & 66.7 \\
\hline \multicolumn{3}{|l|}{ Religion } \\
\hline Christianity & 253 & 93.7 \\
\hline Islam & 17 & 6.3 \\
\hline \multicolumn{3}{|l|}{ Ethnicity } \\
\hline Benin & 109 & 40.4 \\
\hline Etsako & 53 & 19.6 \\
\hline Urhobo & 27 & 10.0 \\
\hline Esan & 24 & 8.9 \\
\hline Yoruba & 24 & 8.9 \\
\hline Igbo & 18 & 6.7 \\
\hline Others* & 15 & 5.5 \\
\hline \multicolumn{3}{|l|}{ Designation } \\
\hline JCHEW & 63 & 23.3 \\
\hline Public health nurse & 62 & 23.0 \\
\hline SCHEW & 50 & 18.5 \\
\hline Nursing officer & 37 & 13.7 \\
\hline Community health officer & 36 & 13.3 \\
\hline Midwives & 22 & 8.1 \\
\hline \multicolumn{3}{|l|}{ Responsibility } \\
\hline Head of unit & 53 & 19.6 \\
\hline Healthcare provider & 217 & 80.4 \\
\hline \multicolumn{3}{|l|}{ Work experience (in years) } \\
\hline$\leq 4$ & 103 & 38.1 \\
\hline $5-9$ & 66 & 24.4 \\
\hline $10-14$ & 54 & 20.0 \\
\hline $15-19$ & 24 & 8.9 \\
\hline$\geq 20$ & 23 & 8.5 \\
\hline
\end{tabular}

Two hundred and forty seven $(91.5 \%)$ of the healthcare workers had received training on immunization. Of this proportion, 84 $(34.0 \%)$ were trained 4 years or more prior to the survey while $57(23.1 \%)$ had training less than a year before the survey. Fourteen $(5.2 \%)$ reported having clinical sessions at their health facility. Of this proportion, $9(64.3 \%)$ stated that they had at least one session on a vaccine related topic. This is shown in table 2. 
International Journal of Advances in Scientific Research and Engineering (ijasre), Vol 6 (3), March -2020

Table 2: Healthcare workers' training on immunization

\begin{tabular}{lll}
\hline Variable & Frequency $(\mathbf{n = 2 7 0})$ & Percent \\
\hline Training on immunization & 247 & 91.5 \\
Yes & 23 & 8.5 \\
No & & \\
Duration since last training $(\mathbf{n}=\mathbf{2 4 7})$ & 57 & 23.1 \\
$<1$ year ago & 60 & 24.3 \\
$1-2$ years ago & 46 & 18.6 \\
$>2-3$ years ago & 84 & 34.0 \\
$\geq 4$ years & & \\
Presence of clinical sessions & 14 & 5.2 \\
Yes & 256 & 94.8 \\
No & & \\
Present vaccination related topic $(\mathbf{n}=\mathbf{1 4})$ & & 64.3 \\
Yes & 9 & 35.7 \\
No & 5 & \\
\hline
\end{tabular}

3.1 Knowledge of Injection Safety

Fifty six $(20.7 \%)$ of the healthcare workers knew the WHO definition of injection safety, with all the healthcare workers indicating HIV as a hazard caused by unsafe injection practice, $243(90.0 \%)$ indicated abscess formation, 237 (87.8\%) mentioned hepatitis B and C while $225(83.3 \%)$ stated paralysis. Two hundred and seventeen $(80.4 \%)$ of the healthcare workers reported that patients, healthcare workers and the public are at risk of unsafe injection practices.

Eighteen $(6.7 \%)$ of the healthcare workers had received training on injection safety and $28(10.4 \%)$ were aware of the injection safety guidelines. Ninety one $(33.7 \%)$ of the healthcare workers reported inadequate provision of syringes as the reason for unsafe injection practices and $42(15.6 \%)$ stated improper disposal

All the healthcare workers mentioned disposable syringes as a type of syringe they were aware of while 79 (29.3\%) were aware of auto disable syringes.

TABLE 3: Healthcare workers' knowledge of injection safety and training on injection safety

\begin{tabular}{|c|c|c|}
\hline Variable & Frequency $(n=270)$ & Percent \\
\hline \multicolumn{3}{|l|}{ Knowledge of the WHO definition of injection safety } \\
\hline Yes & 56 & 20.7 \\
\hline No & 214 & 79.3 \\
\hline \multicolumn{3}{|l|}{ Hazards caused by unsafe injection* } \\
\hline HIV & 270 & 100.0 \\
\hline Abscess formation & 243 & 90.0 \\
\hline Hepatitis B and C & 237 & 87.8 \\
\hline Paralysis & 225 & 83.3 \\
\hline Tuberculosis & 21 & 7.8 \\
\hline Breast cancer & 13 & 4.8 \\
\hline Cholera & 11 & 4.1 \\
\hline \multicolumn{3}{|l|}{ People at risk of unsafe injection practices } \\
\hline Patients, health care worker and public & 217 & 80.4 \\
\hline Patient and health care worker & 38 & 14.1 \\
\hline Health worker and those disposing off the used syringes & 8 & 3.0 \\
\hline Patients only & 7 & 2.6 \\
\hline \multicolumn{3}{|l|}{ Training on injection safety } \\
\hline Yes & 18 & 6.7 \\
\hline No & 252 & 93.3 \\
\hline \multicolumn{3}{|l|}{ Aware of injection safety guidelines } \\
\hline Aware & 28 & 10.4 \\
\hline Unaware & 242 & 89.6 \\
\hline \multicolumn{3}{|l|}{ Stipulated reasons for unsafe injection practices } \\
\hline Inadequate provision of syringes & 91 & 33.7 \\
\hline Improper disposal & 42 & 15.6 \\
\hline Ignorance & 28 & 10.4 \\
\hline
\end{tabular}


International Journal of Advances in Scientific Research and Engineering (ijasre), Vol 6 (3), March -2020

Negligence

Lack of surveillance and supervision

Types of syringes*

Disposable syringes

Auto disable syringes
14

8

270

79

8

262

6

2
5.2

3.0

100.0

29.3

3.0

97.0

75.0

25.0

*Multiple responses

Eight $(3.0 \%)$ of the respondents were aware of the WHO/UNICEF bundling approach and of this proportion, 6 (75.0\%) could correctly define it.

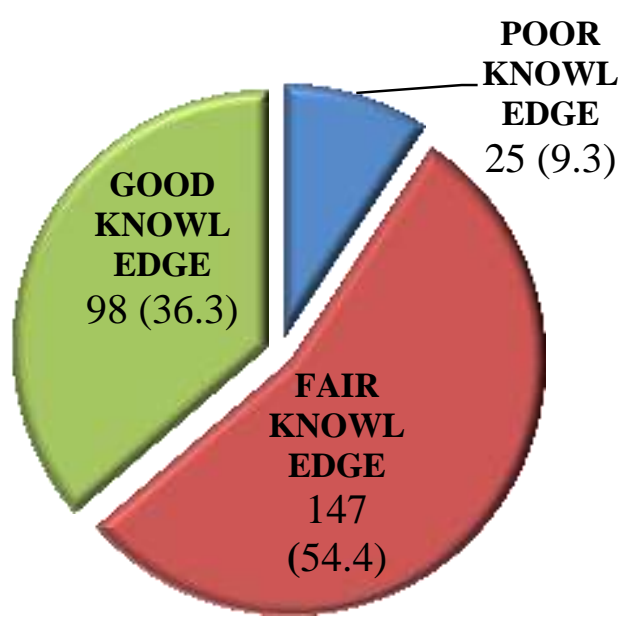

Figure 1: Healthcare workers' composite score for knowledge of injection safety practices

Nine eight (36.3\%) had good knowledge of injection safety practices while $25(9.3 \%)$ had poor knowledge.

A cross-tabulation of the socio demographic characteristics of the respondents and the health care workers knowledge of injection safety in routine immunization (table 4) shows that there is statistically significant $(\mathrm{p}=0.013)$ association between of the healthcare workers aged $30-39$ years who had good knowledge of injection safety practice compared to those aged $50-59$ years.

There was no statistically significant $(\mathrm{p}=0.450)$ between $67(37.2 \%)$ of the female workers who had good knowledge of injection safety practice compared to $31(34.4 \%)$ of their male counterparts. A higher proportion who were designated SCHEWs had good knowledge of injection safety practices compared $9(24.3 \%)$ nursing officers. This association was statistically significant $(\mathrm{p}=$ 0.010).

About half of the healthcare workers with 4 or less years' experience had good knowledge of injection safety practices compared to of those with 20 or more years' experience. This association was also not statistically significant $(p=0.177)$. All the healthcare workers who had received training on safe injection practices had good knowledge of it. This finding was statistically significant $(\mathrm{p}<0.001)$.

Table 4: Association of healthcare workers' knowledge of safe injection practices and their socio-demographic characteristics

\begin{tabular}{llllll}
\hline Variable & \multicolumn{2}{l}{ Knowledge of safe injection } & Test statistic & p value \\
\cline { 2 - 4 } & $\begin{array}{l}\text { Poor } \\
\mathbf{n}(\boldsymbol{\%})\end{array}$ & $\begin{array}{l}\text { Fair } \\
\mathbf{n}(\boldsymbol{\%})\end{array}$ & $\begin{array}{l}\text { Good } \\
\mathbf{n}(\boldsymbol{\%})\end{array}$ & \\
\hline Age (years) & $5(21.7)$ & $8(34.8)$ & $10(43.5)$ & $\chi^{2}=16.096$ & $\mathbf{0 . 0 1 3}$ \\
$22-29$ & $3(3.6)$ & $41(48.8)$ & $40(47.6)$ & & \\
$30-39$ & $11(9.6)$ & $71(61.7)$ & $33(28.7)$ & \\
$40-49$ & $6(12.5)$ & $27(56.3)$ & $15(31.3)$ & \\
$50-59$ & & & &
\end{tabular}


International Journal of Advances in Scientific Research and Engineering (ijasre), Vol 6 (3), March -2020

Sex

Male

Female
53 (58.9)

$94(52.2)$
$31(34.4)$

67 (37.2) $\chi^{2}=1.597$

0.450

19 (10.6)

7 (11.3)

28 (45.2)

$19(52.8)$

$22(59.5)$

15 (68.2)

24 (48.0)

39 (61.9)
$27(43.5)$
$10(27.8)$
9 (24.3)
7 (31.8)
$26(52.0)$
19 (30.2)

$F=23.240$
$24(45.3)$

123 (56.7)

Healthcare provider

Experience (years)

$\begin{array}{ll}\leq 4 & 8(7.8) \\ 5-9 & 5(7.6) \\ 10-14 & 6(11.1) \\ 15-19 & 2(8.3) \\ \geq 20 & 4(17.4)\end{array}$

Training on safe injection practices

Yes $0(0.0)$

No

25 (9.9)

\section{Significant}

Healthcare workers aged less than 40 years were 2.252 times more likely to have good knowledge of injection safety practices compared to their older counterparts. This finding was not statistically significant $(p=0.112)$.

Healthcare workers who received training on injection safety practices were 6.181 times more likely to have good knowledge of injection safety practices. This finding was statistically significant $(\mathrm{p}=0.002)$.

Table 5: Multivariate regression analysis of the predictors of the healthcare workers' knowledge of injection safety practice

\begin{tabular}{|c|c|c|c|c|c|}
\hline \multirow[t]{2}{*}{ Predictors } & \multirow{2}{*}{\multicolumn{2}{|c|}{$\begin{array}{l}\text { B (regressionp-value } \\
\text { coefficient) }\end{array}$}} & \multirow[t]{2}{*}{ Odd Ratio } & \multicolumn{2}{|c|}{ 95\% C.I.for Odd ratio } \\
\hline & & & & Lower & Upper \\
\hline \multicolumn{6}{|c|}{ Age (years) } \\
\hline \multicolumn{6}{|l|}{$\geq 40^{*}$} \\
\hline \multicolumn{6}{|c|}{ Training on injection safety } \\
\hline \multicolumn{6}{|l|}{ No* } \\
\hline Constant & 0.431 & 0.477 & 1.539 & & \\
\hline
\end{tabular}

3.2 HEALTHCARE WORKERS' PRACTICE OF INJECTION SAFETY

None of the healthcare workers reported patients bringing syringes from home.

Two hundred and thirty eight $(88.1 \%)$ reported using standard disposable syringes while $32(11.9 \%)$ used auto disable syringes. 
Seventy two (26.7\%) reported that reconstitution materials were taken from unopened packs, 227 (84.1\%) routinely cleaned the cap of multidose vials with antiseptic solutions and $112(41.5 \%)$ reported storage of temperature sensitive vaccines between $2-$ $8^{\circ} \mathrm{C}$.

Sixty two $(23.0 \%)$ of the healthcare workers reported regular usage of hand gloves, $266(98.5 \%)$ used antiseptic solution to clean skin surface before injection, 134 (49.6\%) usually recap used syringes and all the health workers routinely disposed used syringes. This is shown in table 6)

TABLE 6: Healthcare workers' practice of injection safety and training on injection safety

\begin{tabular}{|c|c|c|}
\hline Variable & Frequency $(n=270)$ & Percent \\
\hline \multicolumn{3}{|c|}{ Patients bring syringe from home } \\
\hline Yes & 0 & 0.0 \\
\hline No & 270 & 100.0 \\
\hline \multicolumn{3}{|l|}{ Type of syringe used } \\
\hline Standard disposable & 238 & 88.1 \\
\hline Auto disable & 32 & 11.9 \\
\hline \multicolumn{3}{|c|}{ Reconstitution materials taken from unopened packs } \\
\hline Yes & 72 & 26.7 \\
\hline No & 198 & 73.3 \\
\hline \multicolumn{3}{|c|}{ Act of cleaning cap with antiseptic for multidose vials } \\
\hline Yes & 227 & 84.1 \\
\hline No & 43 & 15.9 \\
\hline \multicolumn{3}{|c|}{ Keeping temperature sensitive vaccines between $2-8^{\circ} \mathrm{C}$} \\
\hline Yes & 112 & 41.5 \\
\hline No & 158 & 58.5 \\
\hline \multicolumn{3}{|c|}{ Regular usage of new pair of gloves } \\
\hline Yes & 62 & 23.0 \\
\hline No & 208 & 77.0 \\
\hline \multicolumn{3}{|c|}{ Substance used to clean skin surface before injection } \\
\hline Antiseptic & 266 & 98.5 \\
\hline Dry cotton & 4 & 1.5 \\
\hline \multicolumn{3}{|l|}{ Recap used needle } \\
\hline Yes & 134 & 49.6 \\
\hline No & 136 & 50.4 \\
\hline \multicolumn{3}{|l|}{ Dispose used syringe } \\
\hline Yes & 270 & 100.0 \\
\hline No & 0 & 0.0 \\
\hline
\end{tabular}




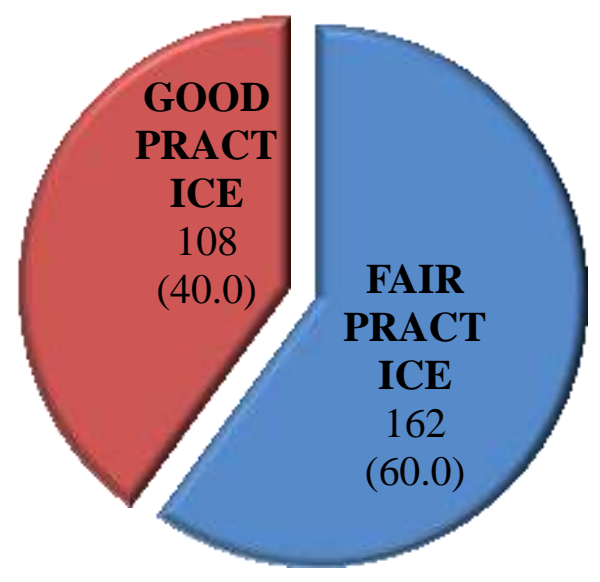

Figure 2: Healthcare workers' injection safety practice

One hundred and eight $(40.4 \%)$ had good practice of safe injection practice while $162(60.0 \%)$ had fair practice.

Twenty three $(47.9 \%)$ of the healthcare workers aged 50 - 59 years had good practice of safe injection practices compared to 8 $(34.8 \%)$ of those aged $22-29$ years. This association was however not statistically significant $(\mathrm{p}=0.335)$.

Forty $(44.4 \%)$ of the male workers had good practice compared to $68(37.8 \%)$ of their female counterparts. This association was not statistically significant $(\mathrm{p}=0.292)$.

Fifteen $(68.2 \%)$ of the midwives had good practice scores for safe injection practices, followed by 18 (50.0\%) of the CHO and 17 $(45.9 \%)$ of the nursing officers. This association was statistically significant $(\mathrm{p}=0.005)$.

Ninety one (41.9\%) of the healthcare providers had good practice scores of safe injection practices compared to 17 (32.1\%) of the heads of units. This association was however not statistically significant $(\mathrm{p}=0.189)$.

Twelve $(50.0 \%)$ of the healthcare workers with work experience of $15-19$ years had good practice scores of injection safety compared to $34(33.0 \%)$ with 4 years or less experience. This association was also not statistically significant $(\mathrm{p}=0.318)$.

There were no statistically significant relationship between the healthcare workers training and knowledge of safe injection practices with their practice of it ( $\mathrm{p}=0.273$ and 0.668 respectively).

Table 7: Healthcare workers' practice of safe injection and their socio-demographic characteristics

\begin{tabular}{|c|c|c|c|c|}
\hline \multirow{2}{*}{ Variable } & \multicolumn{2}{|c|}{ Injection safety practice } & \multirow{2}{*}{ Test statistic } & \multirow{2}{*}{ p value } \\
\hline & Fair n (\%) & Good n(\%) & & \\
\hline \multicolumn{5}{|l|}{ Age (years) } \\
\hline $22-29$ & $15(65.2)$ & $8(34.8)$ & $\chi^{2}=3.396$ & 0.335 \\
\hline $30-39$ & $56(66.7)$ & $28(33.3)$ & & \\
\hline $40-49$ & $66(57.4)$ & $49(42.6)$ & & \\
\hline $50-59$ & $25(52.1)$ & $23(47.9)$ & & \\
\hline \multicolumn{5}{|l|}{ Sex } \\
\hline Male & $50(55.6)$ & $40(44.4)$ & $\chi^{2}=1.111$ & 0.292 \\
\hline Female & $112(62.2)$ & $68(37.8)$ & & \\
\hline \multicolumn{5}{|l|}{ Designation } \\
\hline Public health nurse & $42(67.7)$ & $20(32.3)$ & $\chi^{2}=16.805$ & 0.005 \\
\hline $\mathrm{CHO}$ & $18(50.0)$ & $18(50.0)$ & & \\
\hline Nursing Officer & $20(54.1)$ & $17(45.9)$ & & \\
\hline Midwives & $7(31.8)$ & $15(68.2)$ & & \\
\hline SCHEW & $28(56.0)$ & $22(44.0)$ & & \\
\hline JCHEW & $47(74.6)$ & $16(25.4)$ & & \\
\hline \multicolumn{5}{|l|}{ Responsibility } \\
\hline Head of unit & $36(67.9)$ & $17(32.1)$ & $\chi^{2}=1.726$ & 0.189 \\
\hline Healthcare provider & $126(58.1)$ & $91(41.9)$ & & \\
\hline Experience (years) & & & & \\
\hline
\end{tabular}


International Journal of Advances in Scientific Research and Engineering (ijasre), Vol 6 (3), March -2020

\begin{tabular}{|l|l|l|l|l|}
\hline$\leq 4$ & $69(67.0)$ & $34(33.0)$ & $\chi^{2}=4.717$ & 0.318 \\
\hline $5-9$ & $40(60.6)$ & $26(39.4)$ & & \\
\hline $10-14$ & $28(51.9)$ & $26(48.1)$ & & \\
\hline $15-19$ & $12(50.0)$ & $12(50.0)$ & & \\
\hline$\geq 20$ & $13(56.5)$ & $10(43.5)$ & & \\
\hline \multicolumn{1}{|l|}{ Training on safe injection practices } & & & \\
\hline Yes & $13(72.2)$ & $5(27.8)$ & $\chi^{2}=1.200$ & 0.273 \\
\hline No & $149(59.1)$ & $103(40.9)$ & & \\
\hline Knowledge of injection safety practice & & & \\
\hline Poor & $17(68.0)$ & $8(32.0)$ & $\chi^{2}=0.806$ & 0.668 \\
\hline Fair & $88(59.9)$ & $59(40.1)$ & & \\
\hline Good & $57(58.2)$ & $41(41.8)$ & & \\
\hline
\end{tabular}

\section{Significant}

\section{Discussion}

This study revealed that only one-fifth of the healthcare workers knew the correct WHO definition of injection safety. Similar observations had been noted in a study conducted in Benin City in $2012^{[5]}$ where the knowledge of injection safety among health workers was found to be poor. Almost all respondent were knowledgeable on pathogens transmitted through unsafe injection practices. In a related study done in Kaduna, Nigeria over three quarters of the HCWs could name HIV/AIDS, HBV and HCV as pathogens transmitted by unsafe injection practice. ${ }^{[14]}$ Thus knowledge of specific infections that could result from unsafe injection practices especially HIV and HBV infections was high. Current finding are also consistent with observations made in another study in Ilorin, Nigeria ${ }^{[15]}$ in which over half of the health workers had knowledge of diseases transmissible by unsafe injection practices. Hence, it could be said that there is higher awareness among primary HCWs regarding the risk of disease transmission by unsafe injection practices. The high level of awareness about the mode of transmission of HIV infection may be due to the fear of the disease in the society and increased health education through the mass media concerning the diseases and its mode of spread.

More than a third of the healthcare workers had good knowledge of injection safety practices while more than half had fair knowledge. This finding is comparable with similar study conducted in Benin City. ${ }^{[17]}$ This finding is noteworthy considering the fact that a small proportion of health workers received formal training on safe injection practice. The level of knowledge of injection safety observed in this study may be explained by the fact that nurses constituted a higher proportion of PHC workers and it is likely that their training curriculum would have taught topics such as injection administration, infection control and standard precautions. Furthermore it could also be that constant practice (administration of injections) could have improved their knowledge and the few who may not have received any organized training on injection safety may have acquired relevant knowledge through other channels such as reading about injection safety, causal observance of injection handling practices and informal lessons from more experienced colleagues.

This study showed a significant relationship between cadres, age and training of health workers on one hand and practice of injection safety protocols on the other. Health workers who received training on injection safety practices were more likely to have good knowledge of injection safety practices. This observation is in accordance with findings contained in studies carried out in Benin City ${ }^{[17]}$ and Bangladesh ${ }^{[16]}$.These relationships could provide the platform that could be leveraged upon for improved prevention and control of blood borne pathogens amongst health workers.

The practice of injection safety was generally fair, an observation that is tandem with findings in Kaduna State, Nigeria. ${ }^{[14]}$ Where about a quarter reported regular use of hand gloves, and antiseptic solution for cleaning of skin surfaces before injection.

It has been shown that the use of sterilizable injection equipment is associated with transmission of infections whereas use of single-use disposal syringes/needles results in better injection safety record in health care facilities. ${ }^{[17]}$ In this study, it was found that all therapeutic injection and injectable vaccine were administered using new single use disposable syringes and auto disable syringes, respectively, taken from sealed packs. The syringes were available in sufficient quantity in all selected health care facilities. This is commendable as PHCs adherence to injection safety standards do lead to reduction in the risk of infections associated with the use of sterilizable injection equipment.

Some unsafe practices were observed among healthcare workers. One of which had to do with most of the healthcare workers cleaning the cap of multi dose vials with antiseptic solutions. Swabbing of vial tops with an antiseptic or disinfectant is unnecessary. ${ }^{[17]}$ The septum of vial must be pierced with a sterile needle and the needle should not be left in place in the septum. It was also observed in this study, that vial's septa were pierced with sterile needles but some health workers left such needle in the rubber of multi-dose vials after use. The needle left in the septum of the vial could encourage reuse of the same syringe to repeatedly draw medication, which may lead to contamination of medicament present in the vial hence transmission of pathogens. Furthermore the use of ampoules or single dose vials is preferable to multi-dose vials as multi-dose vials are prone to bacterial 
contamination and its use may be a potential source of infection. If multi-dose vials must be used, it should be limited to single person. However, use of multi-dose vials of vaccines appears to be promoted by government to reduce service cost.

\section{CONCLUSION}

Knowledge of immunization among the health workers was good but knowledge and practice of safety injection was fair

\section{REFERENCES}

1. Safety of Injections: WHO-UNICEF policy statement for mass immunization campaigns, WHO/ EPI/LHIS/7.04 replaced by WHO/V\&B/99.25.

2. O.E. Oguamanam, K.C Diwe. Knowledge, perception and practice of injection safety and healthcare waste management among teaching hospital staff in South east Nigeria: Pan African Medical Journal. 2014; 17:218

3. Federal Ministry of Health. Do No Harm: Injection Safety in the Context of Infection Prevention and Control Trainer's Guide FMOH and JSI/MMIS, Nigeria. 2007;1-126.

4. Federal Ministry of Health. Training Hand-out on Injection Safety in the Context of Infection Prevention and Control for Health Care Personnel. FMOH, JSI/MMIS, Abuja; 2006:3-29.

5. V.E Omorogbe, VO Omuemu, AR Isara. Injection safety practices among nursing staff of mission hospitals in Benin City, Nigeria. Ann Afr Med 2012; 11:36-41

6. H.T Kim, J Johnson, M Loeb. Vaccine herd effects.Scandinavian Journal of Infectious Diseases. 2011; 43:683-689.

7.Perry H, R Weierbach, EL-arifeen S, I Hossain. A comprehensive assessment of the quality of immunization services in one major area of Darka city. Trop Med Int Health.1998; 3(12): 981-92.

8. First do no harm' introducing auto disable syringes and ensuring injection safety in immunization systems of developing countries. WHO/Vand B/0.2.26

9. OO Goodman, SA Aderibigbe, OO Sekoni, GK Osagbemi, TM Akande. Health workers sensitization: effects on perceived quality of immunization services among mothers of under five children in Ilorin. North Central Nigeria. J Prev Med Hyg. 2013; 54:146-52.

10. L Simonsen, A Kane, J Lloyd, M Zaffran, M Kane. Unsafe injections in developing world and transmission of blood borne pathogens: a review. Bull World Health Organ. 1999; 77(10):789-799

11. N Udonwa, AN Gyuse, AJ Etokidem, DS Ogaji. Client views, perception and satisfaction with immunization services at Primary Health Care Facilities in Calabar south-south. Asian Pacific Journal of Tropical Medicine. 2010; $298-301$.

12. Cochrane Sampling Techniques, 3rd Edition. New York: John Wiley and Son 1977.

13.WHO revised injection safety assessment tool. 2008. WHO/eht/08.08:1-10. Tool C. 2-25.

14. O Audu, SA Joshua, O P Enokela. Knowledge and practice of injection safety among workers of Nigerian Prison service Health facilities in Kaduna State American Journal of Public Health Research, 2013;1(7):171-176

15 ES..Kolade Injection safety: knowledge and practice among health workers. West Afr J Med. 2002; 21(1):70-73.

16. AN Ofili, MC Asuzu, OH Okojie. Incidence of blood related work accidents among health workers in government hospital in Benin City Nigeria. JMBR. 2004; 3(1): 59-66.

17. KA Chowdhury, T Roy, BM Faroque, SC Bachar, M Asaduzzaman, N Nasrin. A comprehensive situation assessment of injection practices in primary health care hospitals in Bangladesh. BMC Public Health. 2011; 11:779. Doi.10.1471-2458/11/779. 